Advances in Geosciences, 2, 93-95, 2005

SRef-ID: $1680-7359 /$ adgeo/2005-2-93

European Geosciences Union

(c) 2005 Author(s). This work is licensed

under a Creative Commons License.

\title{
2-D spatial distribution of rainfall rate through combined use of radar reflectivity and rain gauge data
}

\author{
F. Cuccoli, L. Facheris, D. Giuli, and M. Casamaggi \\ CNIT c/o Dept. of Electronics \& Telecommunications, University of Firenze, Firenze, Italy \\ Received: 18 November 2004 - Revised: 9 February 2005 - Accepted: 16 February 2005 - Published: 6 April 2005
}

\begin{abstract}
This paper describes and comments the results obtained applying a data processing method to a joint set of radar and a rain gauge data for estimating the 2-D rainfall field at ground averaged over a given observation time $T$ and over a radar coverage area that includes a rain gauge network. The estimate of the rainfall field is based on the processing of a data set composed by rain gauge and horizontal reflectivity radar data gathered during a rainfall phenomenon. The procedure has been tested on an experimental data set collected in Tuscany in 1999.
\end{abstract}

\section{Introduction}

It is recognised that rainfall rate estimate based on radar measurements is affected by an high degree of uncertainty due to several sources: space-time variability of drop size distribution (from one rainfall event to another and within the same event), variations in space and time of reflectivity with height, radar signal attenuation due to propagation in the precipitation rainfall, etc. (Anagnostou, 1999). Moreover, the way commonly used to assess the reliability of the rainfall radar estimates is to "compare" them with data provided by an ensemble of raingauges placed in the radar coverage area (Anagnostou, 1999; Aydin, 1990; Scarchilli, 1999). A novel raingauge-radar data processing method was proposed by the authors (Cuccoli et al., 2003) for the estimate of the spatial distribution of the rainfall rate $R_{T}(x, y)$ over an area covered by a meteorological radar and a raingauge network during a given observation time $T$. Such method processes the (instantaneous) absolute reflectivity $Z$ ( $H$ polarization, in the case of the system used here) as provided by the radar and the estimates of rainfall $R$ as provided by raingauges, both collected during a given observation time $T$, in order to compute the rainfall rate $R_{T}(x, y)$ as:

$\log \left(R_{T}(x, y)\right)=A_{T}(x, y)+B_{T}(x, y) \log \left(Z_{T}(x, y)\right)$

Correspondence to: F. Cuccoli

(cuccoli@achille.det.unifi.it) where $Z_{T}(x, y)$ is a space-time average function of the instantaneous horizontal reflectivity maps (PPI scans) gathered during the observation time $T$, while $A_{T}(x, y)$ and $B_{T}(x$, $y$ ) are coefficients that are determined by means of ad hoc correlation functions between space-time "average" values of raingauge data and absolute reflectivity data. In this paper we discuss some results obtained applying the method to a radar and rain gauge data set acquired during a 1999 storm over Tuscany.

\section{Description of the data processing procedure}

Once defined the extension of the precipitation volume to be correlated to the raingauges, the procedure developed allows the estimation of the rainfall rate on a time interval basis $T$, in order to obtain a number of pairs Z-R through which the coefficients $A_{T}\left(x_{k}, y_{k}\right)$ and $B_{T}\left(x_{k}, y_{k}\right)$ are computed, corresponding to any given raingauge location $\left(x_{k}, y_{k}\right)$.

The method does not make use of a priori parameters and the relationship between reflectivity and rainfall rate is variable in both time and space. This kind of approach allows to account for the evolution of the precipitation phenomenon since the simultaneous and time-continuous use of raingauge and radar reflectivity time series allows to modify in real time the relationship between the rainfall rate and the radar observation.

Here a synthesis of the data processing procedure is reported, which is described in better detail in (Cuccoli et al., 2003). First of all, a reference radar volume is pre-assigned for all the rain gauge positions. Such volume is defined as the number of adjacent radar cells above the ground rain gauge position. Then a set of time parameters, the processing time $T_{w}$ and the shift time $T_{s}$, is assigned together to the observation time $T$. $T_{w}$ and $T_{s}$ allow the management of a mobile processing window inside the observation time $T$. For the $k$-th raingauge, a number $n p$ of time averaged rain rate values $R W_{p}^{(k)}(p=1 \ldots n p)$ and a corresponding time uncertainty parameter $\sigma_{R p}^{(k)}$ are computed. Later on, the same 

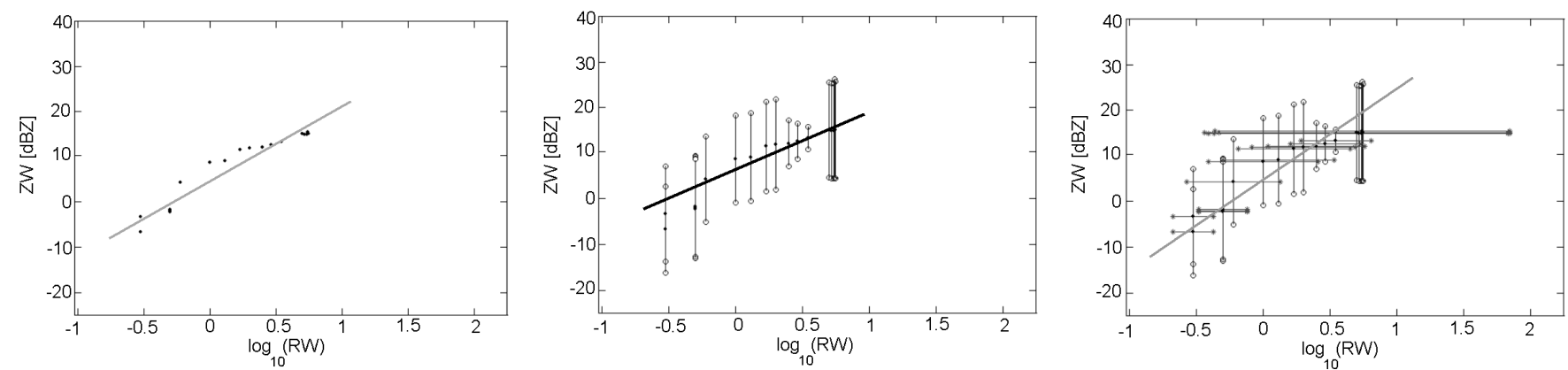

Fig. 1. Example of $Z-R$ regression computation: (left) linear regression, (center) least square, (right ) effective variance method.

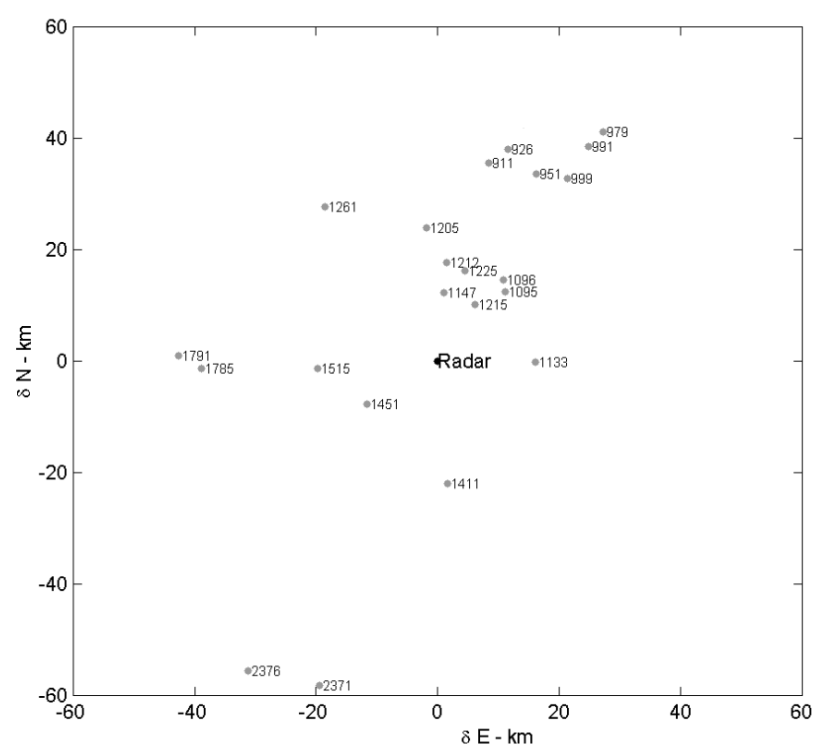

Fig. 2. Geographical disposition of the 22 raingauges with respect to the radar position.

number $n p$ of averaged reflectivity radar values $Z W_{p}^{(k)}$ are computed together with their space time uncertainty parameters $\sigma_{Z p}^{(k)}$. Therefore, for each rain gauge a number $n p$ of $\left(Z W_{p}^{(k)}, R W_{p}^{(k)}\right)$ pairs with their uncertainty parameters are generated in the observation time $T$. The number $n p$ depends on $T, T_{s}$ and $T_{w}$ (i.e. the combination $T=240, T_{w}=120$ and $T_{s}=60 \mathrm{~min}$ gives $\left.n p=4\right)$. The uncertainty parameters $\sigma_{R p}^{(k)}$ and $\sigma_{Z p}^{(k)}$ respectively account for non homogeneity and non stationary of the precipitation phenomenon over the $k^{\text {th }}$ raingauge location.

To relate $Z W_{p}^{(k)}$ and $R W_{p}^{(k)}$ three approaches can be followed. In the first, both are ideally supposed to be not affected by uncertainty for all the $n p$ pairs, namely they are considered equally reliable and no uncertainty indexes are needed, and therefore a standard linear regression method is sufficient. In the second approach, $Z W_{p}^{(k)}$ and $R W_{p}^{(k)}$ are assumed without and with uncertainty, respectively, for all the $n p$ pairs; then the uncertainty index $\sigma_{Z p}^{(k)}$ is used as a score for the conditions of non homogeneity and non stationariety on the radar dataset. In this case, a standard least squares method is used.

In the last approach, both $Z W_{p}^{(k)}$ and $R W_{p}^{(k)}$ are assumed with uncertainty for all the $n p$ pairs, and $\sigma_{R p}^{(k)}$ and $\sigma_{Z p}^{(k)}$ are used in order to account for the conditions of non homogeneity and non stationarity on the $R W_{p}^{(k)}$ dataset and for the non stationarity on the $Z W_{p}^{(k)}$ dataset, respectively. In this case, the effective variance method (Orear, 1982) is used. Figure 1 shows an example of $Z-R$ regression computation considering such approaches.

The result of the regression is a straight line for every raingauge location whose parameters, the slope and the intercept, are the coefficients $A_{T}$ and $B_{T}$ of the Eq. (1) for the location $(x, y)$ of the $k^{\text {th }}$ raingauge.

\section{Performance analysis}

The performance analysis of the proposed method has been made on the whole radar and raingauge data set related to the rainfall phenomenon occurred over Tuscany (Italy) on 21 October 1999 from 11:40:00 to 22:20:00 local time, observed by the dual polarization radar POLAR 55C sited in Montagnana (Firenze, Tuscany). The sampling time is 15 and $10 \mathrm{~min}$ for the raingauges and the radar data, respectively. Figure 2 shows the spatial disposition of the 22 raingauges used in this paper assuming the radar located in $(0,0)$.

We considered several combinations of time parameters ( 1 to $20 \mathrm{~h}$ step $20 \mathrm{~min}$ for $T, 10 \mathrm{~min}$ to $3 \mathrm{~h}$ step $10 \mathrm{~min}$ for $T_{w}, 5$ to $20 \mathrm{~min}$ step $5 \mathrm{~min}$ for $T_{s}$ ) and all the three regression computation methods discussed in the previous section. For each combination, we selected 18 raingauges for the computation procedure and 4 raingauges for comparison. For each observation time value, we selected the parameters $T_{w}$ and $T_{s}$ that give regression errors lower than $20 \%$ among all the possible combinations of time parameters.

In order to make the test statistically significant, all possible combinations of computation and comparison raingauge ensembles, among the available 22 raingauges, were considered. About 350 different combinations of comparison cases were obtained for each set of time parameters. 


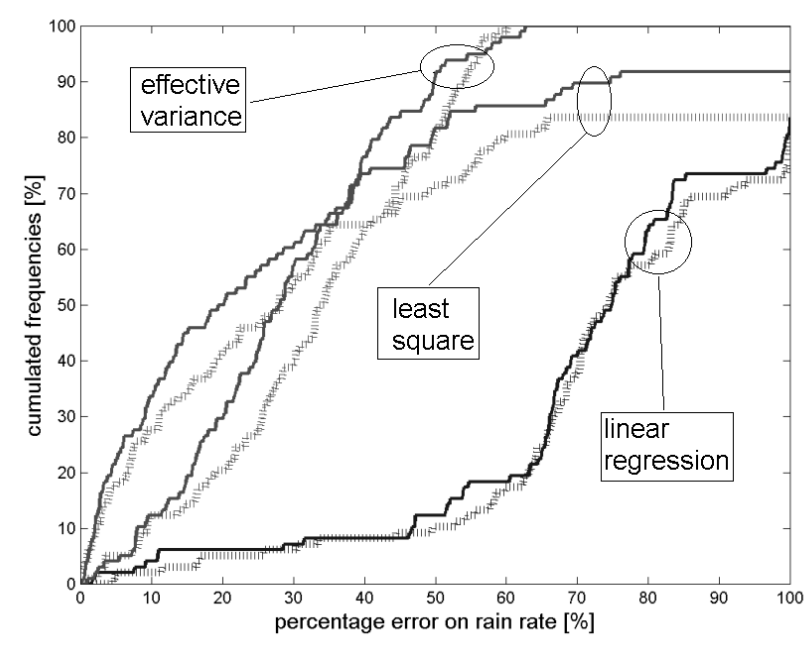

Fig. 3. Estimation error of the rainfall rate considering all the possible validation ensembles, composed by 4 raingauges, and the computation ensembles, composed by 18 raingauges. Black line: timespatial bilinear interpolation, gray line: spatial interpolation.

The values of the coefficients $A_{T}$ and $B_{T}$ corresponding to a comparison raingauge site are computed considering two different 2-D interpolation methods: the first is a standard bilinear interpolation on the $A_{T}$ and $B_{T}$ of the 4 computation raingauges that are closer to the comparison raingauge, the second is still based on a spatial bilinear interpolation, but accounts also for a time correlation index between the radar sequences over the locations of the comparison and computation raingauges. The complete results are summarized in Fig. 3 in terms of percentage error of the rainfall rate estimation over the comparison raingauge site, versus the cumulated frequencies. Notice in particular that:

a) the effective variance method performs best to find the slope and intercept coefficients, independently of the 2D interpolation method used;

b) of the two 2-D interpolation methods, that based on the time correlation index is slightly better;

c) when using the effective variance method, the estimation error of the rainfall rate is always lower than $60 \%$, independently of the set of time parameters chosen for the processing procedure and of the ensembles of comparison/computation raingauges.

\section{Conclusions}

The procedure proposed in this paper allows the estimation of the rainfall rate over an area covered by a meteorological radar and a raingauge network. Such procedure is based on the local space-time comparison of the radar horizontal reflectivity through the raingauge data. The procedure has been applied on an a solid radar-raingauge data set obtained during a precipitation event occurred in Tuscany (Italy) in 1999. The results show that the 2-D distribution of the rainfall rate can be estimated always with error lower than $60 \%$. Many other tests with different data set corresponding to different precipitation phenomena must be done in order to quantify the general performance. Such tests will allow the refinement and the tuning of all the parameters involved in the data processing procedure, especially concerning the relationship among $T_{W}, T_{s}$ and the observation time $T$. After that a profitable comparison to other existing radar processing techniques will be possible in order to quantify the potential of the proposed procedure.

Acknowledgements. The authors would like to thank L. Capannesi for his technical support. This work was sponsored by the CNRGNDCI (National Group for the Defence from Hydrogeological disasters of the Italian National Research Council).

Edited by: L. Ferraris

Reviewed by: anonymous referees

\section{References}

Anagnostou, E. N., Krajewski, W. F., and Smith, J.: Uncertainty Quantification of Mean-Areal Radar-Rainfall Estimates, J. Atmos. Oceanic Technol., 16, 206-215, 1999.

Aydin, K., Lure, Y. M., and Seliga, T. A.: Polarimetric radar measurements of rainfall compared with ground-based gauges during maypole' 84 , IEEE transactions on geoscience and remote sensing, 28, 4, 443-449, 1990.

Cuccoli, F., Facheris, L., Giuli, D., and Mossa ,F.: Estimating the spatial distribution of rainfall rate through the combined use of radar reflectivity and rain gauge data, Proc. of 5-th Plinius Conference on Mediterranenan Storms, Aiaccio, Corsica, France, 13 October 2003, 385-392, 2003.

Orear, J.: Least squares when both variables have uncertainties, Am. J. Physics, 50(10), 912-916, 1982.

Scarchilli, G., Gorgucci, E., and Chandrasekar, V.: Detection and estimation of reflectivity gradients in the radar resolution volume using multiparameter radar measurements, IEEE transactions on geoscience and remote sensing, 37, 2, 1122-1127, 1999. 